\title{
How Effortful Are Interpreters in Translation Related Reading Tasks?: An Eye-Tracking Study*
}

\author{
WANG Jia-yi \\ Hunan Institute of Engineering, Xiantan, China; University of Macau, Macau, China \\ HE Yan \\ University of Macau, Macau, China
}

\begin{abstract}
Readingto comprehend the source text is a necessary part in translation process. However, the cognitive processing in various reading tasks related to translation is far from well-understood. The present study investigated interpreters' eye movement behavior in E-C language pair across different reading tasks. The participants are instructed to perform four tasks involving reading for specific purposes. The four tasks are as follows: (1) reading for comprehension (monolingual); (2) reading for summary; (3) reading in preparation for translating; and (4) reading while speaking a translation (sight translating). The results showed that reading purposes have a clear effect on interpreters' eye movement behaviors. By tasks both groups of interpreters spent more task time, more and longer fixations as they dealt with increasingly cognitive-demanding tasks. Across groups student interpreters spend more time, more and longer fixations than do professionals in most of the tasks. The study revealed that the increasing cognitive efforts required by reading is dependent on various reading tasks and translation expertise, which provided tentative implications for understanding and modelling the way interpreters read. The study also provided evidence for the validity of eye-tracking as a methodology in different translation modalities.
\end{abstract}

Keywords: eye movement, reading tasks, interpreter, cognitive effort

\section{Introduction}

Comprehension of a text comes from reading. Skilled readers usually set "standards of coherence" that allow them to flexibly allocate resources to generate appropriate strategies in accord with specific reading goals. That is, readers may have different criteria for how well they must comprehend a text when studying for an exam as opposed to when reading for fun; and subsequently these criteria, or standards of coherence, influence the kinds of cognitive processes readers engage in (Linderholm et al., 2008).

Theories of translation put forward that three are at least three major processes occur during the translation taskwhich includes: Source Language (ST) reading and comprehension, switch between two linguistic codes, and

\footnotetext{
*Acknowledgments: This study was supported by MYRG2015-00150-FAH, MYRG2016-00096-FAH, and MRG2017-00139-FAH grants from the University of Macau, and Hunan Social Science Fund of China (Grant No. XSP17YBZZ022).

WANG Jia-yi, Ph.D. student, Centre for Studies of Translation Interpreting and Cognition, University of Macau; Associate Professor, College of Foreign Languages, Hunan Institute of Engineering.

HE Yan, Ph.D. candidate, Centre for Studies of Translation Interpreting and Cognition, University of Macau.
} 
production of the Target Language (TL). So readingto comprehend the source text is a necessary part in translation process. However, as Alves et al. (2010, p. 178) proposes "Reading as a cognitive activity related to translation has scarcely been invested." To know how reading varies according to different reading purposes, Jakobsen \& Jensen conducted an experiment that a group of six professional translators and a group of six translation students read four similar texts on the same news topic while their eye movements were tracked. They concluded that "reading purpose had a clear effect on eye movements and gaze time" (Jakobsen \& Jensen, 2008, p. 120). For both groups, task time, fixation frequency, gaze time and average fixation duration showed a consistent, linear progression from task to task. Following a similar design to the one used by Jakobsen \& Jensen (2008), Alves et al. (2010) conducted a research by comparing their results to Jakobsen \& Jensen's. Interestingly, Alves et al. (2010) got no apparent differences across tasks.

"Replication of experiment is thought to offer the possibility of strengthening the generalization power for translation process research, and is therefore, desirable" (Alves et al., 2010, p. 179). Based on Jakobsen \& Jensen (2008) and Alves et al. (2010), by means of an analogous experimental design, this study aims at: (1) comparing our results with the findings reported in Jakobsen \& Jensen (2008) and Alves et al. (2010); and (2) answering the question: do reading purpose had a clear effect on interpreters'eye movement behavior in E-C language pair? If so, interpreters will spend more task time, more and longer fixations as they dealing with increasing complexity of the tasks requested. If differences were found, we would look for probable causes of such differences.

\section{Overview of Research into Reading inTranslation Studies}

Research on reading has long been done on monolingual reading of text (Rayner \& Pollatsek, 1989; Rayner, 1998). Reading as a cognitive related processing in translation has seldom been investigated due to limited number of methodological tools. To address the role of reading in translation, Shreve et al. (1993) investigated the differences in reading-for-translation, reading-for-paraphrasing and reading-for-comprehension when translators perform the three tasks. Their study showed a slight increase in time in anticipation problems related to translation and a significant variability in the way translators "read for translation". By comparing the process of reading for translation with general (monolingual) reading, Danks and Griffin (1997) put forward that reading depends on the reader's level of skill and processing capacity. Bajo and colleagues conducted a series of studies to investigate the relationship between text comprehension and transfer in translation process by comparing the differences of reading-for-translation and reading-for-repetition from the perspective of psycholinguistic standpoint (Macizo \& Bajo, 2004; Macizo \& Bajo, 2006; Ruiz et al., 2008). Their findings suggest that reading for translation results in the co-activation of the two linguistic systems. They argue that the results from these studies are in line with horizontal rather than vertical translation.

Decades ago scholars have started to use eye tracking as a methodology in research of reading processes (Rayner \& Pollatsek, 1989; Rayner, 1998; Brychtova \& Coltekin, 2016), and "several basic facts about eye movements in reading have been convincingly documented" (Jakobsen \& Jensen, 2008, p. 103). The relationship between what the eyes are doing at any given moment in time and what the mind is processing was originally assumed by Just and Carpenter (1980) when they formulated the eye-mind and the immediacy assumptions. They saw a straightforward relationship between what a person's eyes were fixating and what the mind was attending to and processing.In recent 10-11 years, eye tracking methodology has been introduced into translation 
process research. A translator's eye movements give a detailed picture of the complex processing involved in constructing meaning from a string of words or characters and representing that meaning in the words or characters of a new language (Jakobsen, 2017). A variety of topics have been discussed through the analysis and exploration of eyetracking data. These topics include: translation expertise, competence and experience, cognitive effort, reading in translation, human-computer and human-information interaction, metaphor processing, directionality, reception of translated material etc. (e.g., Carl, Bangalore, \& Schaeffer, 2016; Göpferich, Jakobsen, \& Mees, 2008; Gruzca, Płużyczka \& Zając, 2013).

Jakobsen and Jensen (2008) were among the first authors to attempt to use eye-tracking technology to examine translation reading. They compared reading during translation with other kinds of translation reading. In their experiment, a group of six Danish translation students and a group of six professional translators were asked to carry out four tasks involve reading for specific purposes at a speed with which they would normally work. The four tasks are reading for comprehension, reading in preparation for translating, reading while speaking a translation (sight translating) and reading while typing a writing translation. The study found that reading during translation involves considerably longer task time, more and longer fixations than reading for comprehension, reading in preparation for translating, and reading while speaking a translation (i.e., sight translation). The study concluded that "reading purpose had a clear effect on eye movement and gaze time" (Jakobsen \& Jensen, 2008, p. 120). Alves et al. (2010) also examined different kinds of translation reading, namely reading for comprehension, reading with the purpose of producing an oral summary, and translating a text orally while reading it (i.e., sight translation). Their study followed a similar design to the one in Jakobsen and Jensen (2008), but introduces an additional condition in an attempt to "test their methodology and exam eye-tracking data in different reading performance associated with different tasks" (Alves et al., 2010, p. 176). Contrary to their expectations, the main findings reported in Alves et al. (2010) weren't consistent with the findings reported in Jakobsen and Jensen (2008) , except that: (1) students spent more time on average performing all tasks than professionals; and (2) students and professionals had longer fixations in sight translation than in the two other tasks. They argue that the differences "might be due to proficiency levels and familiarity with task demands among the Danish and Brazilian experimental groups" (Alves et al., 2010, p. 191). They also pointed out that perhaps the use of different software packages is one contributor to the differences between the findings of the two studies.

It can be seen that the above two studies did not reach a consistent conclusion in answering whether the purpose of reading affects the translator's reading processing. The cognitive processing in various reading tasks related to translation is far from well-understood. Bearing in mind that "replication of experiment is thought to offer the possibility of strengthening the generalization power for translation process research, and is therefore, desirable" (Alves et al., 2010, p. 179), we proposed the present study by means of an analogous experimental design based on Jakobsen \& Jensen (2008) and Alves et al. (2010) to see if reading purpose had a clear effect on interpreters' eye movement behavior in E-C language pair and how effortful are interpreters in translation related reading tasks. 


\section{Present study}

\subsection{Participants}

A total of 12 subjects participated in the study. Of these 12 subjects, six were MTI (Master of Interpreting and Translation) students and six were professional interpreters. All subjects had Chinese as their L1 and translated primarily into English as their L2. Twelve subjects, six translation students and six professional interpreters, were recruited to participate. All subjects received initial training to become familiar with the experimental environment and the eye-tracking equipment.

\subsection{Hypotheses}

We are assuming that the observable, measurable data that can be gained from eye tracking are indicators of unobservable cognitive processes happening in the subjects' mind during the translation tasks. In this assumption we rely on previous research on eye movements. Task time, fixation count, average fixation duration were interpreted asindicators of cognitive effort (Jakobsen \& Jensen, 2008; Pavlović \& Jensen, 2009; Ferreira et al., 2013). We thus used threekinds of data obtainable from eye tracking in order to gain insights into the cognitive processes of our subjects. The following variables were explored:

(a) "task time", that is, the total time it took the subjects to complete the given reading task.

(b) "fixation count", that is, the total fixations of the subjects to complete the given reading task.

(c) "average fixation duration", which is based on the gaze time value andthe total number of fixations.

With these assumptions in mind, we formulated the following hypotheses:

H1: Subjects would spend more time as they dealt with increasing complexity of the tasks requested; students would spend more time than professionals do when they perform the same task.

H2: Subjects would have a higher number of fixations as they dealt with increasing complexity of the tasks requested; students would have a higher number of fixations than professionals do when they perform the same task.

H3: Subjects would have longer fixations as they dealt with increasing complexity of the tasks requested; students would have longer fixations than professionals do when they perform the same task.

\subsection{Research Design and Methodology}

In order to test the above hypotheses, we created the following research design.

\subsubsection{Eye-tracking equipment}

The tracking of our test subjects' eyes was carried out with the Tobii 300 eye tracker, which is a remote tracker that allows unrestrained head movement. Texts were displayed in 16-point, double-spaced Times Roman font on a 23 " LCD screen at $1920 \times 1080$ pixels. Subjects sat at a distance of about $60 \mathrm{~cm}$ from the screen, and there is no head or chin rest was used.

\subsubsection{Texts}

The text selected for the experiment had an average number of 193 words and were identical to those used by Jakobsen \& Jensen's (2008) and Alves et al's (2010) study. Four texts with the same difficulty from the general news domain are about the end of Tony Blair's term as British Prime Minister. The orthographic, lexical and syntactic complexity of the four texts were measured by using several standard tools to stipulate the texts to be as authentic and as comparable as possible (Jakobsen \& Jensen, 2008; Alves et al., 2010). 


\subsubsection{Tasks}

Twelve participants have their reading processes monitored and recorded using an eye tracker. The participants are instructed to perform four tasks involve reading for specific purposes. To neutralize any skewing effects caused by differences in the texts, we rotated the task-text combination systematically as done by Jakobsen and Jensen (2008) so that participant A performed Task 1 with Text 1, Task 2 with Text 2, etc.; participant B performed Task 1 with Text 2, Task 2 with Text 3 , etc. Participants were asked to carry out all tasks at the speed with which they would normally work.

The four tasks and the task sequence are as follows:

Task 1: Reading for comprehension (monolingual). Participants were asked to read the text "for comprehension" in the same way as they would normally read a news article. The task ended when participants typed any key on the keyboard. Their comprehension was not subsequently tested.

Task 2: Reading for summary.Participants were asked to read the text "for summary". The reading task ended when participants typed any key on the keyboard. Then Participants began to producing an oral summary of a text.

Task 3: Reading in preparation for translating was a reading task like Task 1, but here participants were told that they would be asked to translate the text after reading it. (Participants were in fact not asked to translate the text they had read in Task 3.)

Task 4: Reading while speaking a translation (sight translating). Participants were required to combine reading of the text with producing a spoken translation of it into their native Chinese. (For all participants, all translations were $\mathrm{L} 2$ to $\mathrm{L} 1$ tasks.)

\subsubsection{Eye tracking data analysis and settings}

A Tobii 300 eye tracker was used to register the eye movements of six translation students and six professionals as they read the four texts by executing four different tasks. In most cases the Tobii I-VT fixation filter will correctly classify fixations in recordings made with previous versions of Tobii Studio. So Tobii I-VT filter can now analyze the raw tracking data recorded by the eye tracker in present study.

The subjects were additionally given short warm-up tasks prior to the four main tasks to help them get used to the experimental setting, the computer, the eye tracker, and so on. The four tasks took place on the same day, after a short break.

\section{Findings and Analysis}

In this section, findings are presented separately for different tasks regarding total task time, number of fixation count and length of fixation duration.

\subsection{Task Time}

There was a very consistent increase in mean task time for all subjects across the four tasks as shown in Table $1(79<120<133<253)$. 
Table $1^{1}$

Mean Task Time (in seconds) for Subjects by Task

\begin{tabular}{llll}
\hline Tasks & All & Professionals & Students \\
\hline Task 1: Reading for comprehension & 79 & 65 & 92 \\
Task 2: Reading for Summarizing & 120 & 101 & 139 \\
Task 3: Reading for Translation & 133 & 98 & 169 \\
Task 4: Sight Translation & 253 & 191 & 316 \\
\hline
\end{tabular}

A tentative statistical paired samples $t$ test of task time findings suggested that the mean differences across tasks for all participants were significant except for the tasks between Task 2 and Task 3 . The mean task time increase from Task 1 to Task 2 was highly significant $(\mathrm{p}<0.01, \mathrm{t}=-3.952$, and $\mathrm{df}=11)$. Likewise, the mean task time increase from Task 2 to task 4 and task 3 to task 4 were highly significant with $\mathrm{p}<0.001, \mathrm{t}=-5.428, \mathrm{df}=11$, and $\mathrm{p}<0.001, \mathrm{t}=-5.409, \mathrm{df}=11$ respectively. However, the difference of mean task time between Task 2 and Task 3 was not significant with $\mathrm{p}>0.05, \mathrm{t}=-0.752$, and $\mathrm{df}=11$.

It was found that the group of professionals were faster on average in all the tasks than the group of students. And for both groups, there was a very consistent increase in task time across the four tasks. The average task time (reading time) for Task 1 was 65 seconds for professional translators and 92 seconds for translation students. With about 200 words in the texts, this means that professionals read 3 words per second while students read 2 words per second. The average task time (reading time) for Task 2 was considerably longer than it for Task 1 . Here, professionals spent 101 seconds on average, while translation students spent 139 seconds. The average task time for Task 3 was 98 for professionals and 169 for students. The average task time for Task 4 was more than triple that for Task 1 and approximately twice that for Task 2 and 3. There was considerable variance among participants within both groups, but again professionals were considerably faster than translation students, the average for professionals being 191 seconds and 316 seconds for translation students.

\subsection{Fixation Count}

Table 2 shows the same tendency as it in mean fixation count that a consistent increase in numbers for all subjects across the four tasks $(261<384<428<730)$.

The statistical paired samples $t$ test of fixation count findings showed that the mean differences across tasks for all participants were significantexcept for the tasks between Task 2 and Task 3 . The mean fixation count increase from Task 1 to Task 2 was highly significant $(\mathrm{p}<0.01, \mathrm{t}=-3.551$, and $\mathrm{df}=11)$. Likewise, the mean task time increase from Task 2 to task 4 and task 3 to task 4 were highly significant with $\mathrm{p}<0.01, \mathrm{t}=-4.307, \mathrm{df}=11$, and $\mathrm{p}<0.01, \mathrm{t}=-3.990, \mathrm{df}=11$ respectively.Yet, there is no significant difference of mean task time between Task 2 and Task 3 with $\mathrm{p}>0.05, \mathrm{t}=-0.853$, and $\mathrm{df}=11$.

As expected, professionals had much fewer fixations than translation students overall in all tasks. And for both groups, there was a very consistent increase in fixation count across the four tasks except for the fixations in Task 2 and Task 3 which are the same for professionals.

In Task 1, the average fixation count for professionals was 225 and for students was 297. In Task 2, it is 328 for professionals and 441 for students. In Task 3, it is 328 for professionals and 527 for students. The largest number of fixations occurred in Task 4. It is increased to 576 for professionals and 884 for students.

\footnotetext{
${ }^{1}$ note: The data (in Table 1-6) has been partially published in "Cognitive Mechanism of Interpreters' Reading Processing: An Eye-tracking Based Empirical Study" (Wang et al, 2018)
} 
Table 2

Mean Fixation Count for Subjects by Task

\begin{tabular}{llll}
\hline Tasks & All & Professionals & Students \\
\hline Task 1: Reading for comprehension & 261 & 225 & 297 \\
Task 2: Reading for Summarizing & 384 & 328 & 441 \\
Task 3: Reading for Translation & 428 & 328 & 527 \\
Task 4: Sight Translation & 730 & 576 & 884 \\
\hline
\end{tabular}

\subsection{Fixation Duration}

The mean fixation durations throughout the execution of the four tasks showed a progression similar to that already found with respect to task time and fixation count. The average for all participants in Task 1 was 293 milliseconds, increasing to 300 milliseconds in Task 2, to 298 seconds in Task 3, and to 342 seconds in Task 4 . The figures are summarized by group in Table 3 .

Yet, the statistical paired samples $t$ test of fixation duration findings showed that the increases from Task 1 to Task $4(\mathrm{p}<0.05, \mathrm{t}=-2.537$, and $\mathrm{df}=11)$, from task 2 to task $4(\mathrm{p}<0.05, \mathrm{t}=-2.716$, and $\mathrm{df}=11)$ and from task 3 to task $4(\mathrm{p}<0.05, \mathrm{t}=-2.765$, and $\mathrm{df}=11)$ were significant. There is no significant difference of mean fixation durations between Task 1 and Task 2, Task 1 and Task 3, and Task 2 and Task 3.

Interestingly, professionals had much shorter fixations than students in Task 1, Task 2 and Task 3. Yet professionals had slightly longer fixations than students in Task 4. For students, there was a very consistent increase in mean fixation duration across the four tasks. For professionals, like the tendency in mean task time there was a consistent increase in Task 1, Task 2 and Task 4, or Task 1, Task 3 and Task 4. Yet, it slightly decreases in Task 2 and Task 3.

Table 3

Mean Fixation Duration (in milliseconds) for Subjects by Task

\begin{tabular}{llll}
\hline Tasks & All & Professionals & Students \\
\hline Task 1:Reading for comprehension & 293 & 274 & 313 \\
Task 2: Reading for Summarizing & 300 & 287 & 315 \\
Task 3: Reading for Translation & 298 & 277 & 320 \\
Task 4: Sight Translation & 342 & 349 & 335 \\
\hline
\end{tabular}

\section{Discussion}

\subsection{Hypothesis 1}

Hypothesis 1 that subjects would spend more time as they dealt with increasing complexity of the tasks requested and students would spend more time than professionals do when they perform the same task was confirmed as has been discussed in 3.1.

A comparative study with Jakobsen \& Jensen (2008) and Alves et al. (2010) shown in Table 4 indicated that our finding that there was a very consistent increase in mean task time for all subjects across the four tasks confirmed with Jakobsen and Jensen's (2008) results. Our finding that students spend more time than professionals do when they perform the same task confirmed both Jakobsen and Jensen's (2008) and Alves et al.'s (2010) findings.The subjects are requested to read the texts for comprehension, for summary and for 
translation, but in fact they are not asked to answer comprehension questions, give a summary and do a translation. That's to say, the only difference among these three tasks was the different expectation (comprehension, summary or translation) raised in participants (for comprehension, for summary or for translation). Task 4 (sight translation) requires participants highest cognitive effort than other tasks due to the fact that they combined reading of the text with producing a spoken translation as it confirmed in all the three studies.

Table 4

Comparison of Mean Task Time in Three Studies

\begin{tabular}{lll}
\hline & By Tasks & By Groups \\
\hline J \&J & Task $1<$ task $2<$ task 4 & $\mathrm{~S}>\mathrm{P}$ \\
Alves & Task $3<$ task $1<\operatorname{task} 4$ & $\mathrm{~S}>\mathrm{P}$ \\
Present Study & Task $1<\operatorname{task} 2<\operatorname{task} 3<\operatorname{task} 4$ & $\mathrm{~S}>\mathrm{P}$ \\
\hline
\end{tabular}

\subsection{Hypothesis 2}

Table 5 is the comparison of findings onmean fixation count in three studies. Unlike the findings reported in Alves et al (2010) that there is " no apparently clear-cut differences across groups and across tasks", the present study exhibits the similar findings as Jakobosen and Jensen (2008) that the mean differences across tasks were significant and students have a higher number of fixations than professionals do when they perform the same task. So, hypothesis 2 that subjects would have a higher number of fixations as they dealt with increasing complexity of the tasks requestedand students would a higher number of fixations than professionals do when they perform the same task was confirmed.

As has been discussed in 4.1 that the only difference among Tasks 1, 2, and 3 was the different expectations raised in participants. That is, the expectation of the participants is to understand the meaning after reading, to summarize after reading, or to translate after reading. It can be seen that the differences in the eye movement behavior in the reading process was caused by the different reading expectations generated by the participants after being informed of the reading task. That is, the different reading purposes affect the reading process. This conclusion is consistent with the study by Arnt \& Jensen (2008). Compared with the other three tasks, there were more fixations in Task 4 (sigh translation). The possible reason was that theparticipants needed to construct the meaning of the source text in the brain, and at the same time monitor the oral output of the target text online. For example, what information has been successfully translated and what remains to be processed further. More fixations and the increase of regressions were caused by the need to ensure management of ST comprehension and TT text production. As Jakobosen and Jensen (2008) suggested, the additional gaze activity was required to ensure that the information represented in the participant's flow of speech was dynamically matched to the string of text on screen.

Table 5

Comparison of Mean Fixation Count in Three Studies

\begin{tabular}{lll}
\hline & By Tasks & By Groups \\
\hline $\mathrm{J} \& \mathrm{~J}$ & Task $1<$ Task $2<$ Task 4 & $\mathrm{~S}>\mathrm{P}$ \\
Alves & No difference & No difference \\
Present Study & Task $1<$ Task $2<$ Task3 $<$ Task 4 & $\mathrm{~S}>\mathrm{P}$ \\
\hline
\end{tabular}




\subsection{Hypothesis 3}

Table 6 shows that there are similarities and differences when comparing the findings of Jakobsen and Jensen (2008), and Alves et al (2010) with the results of the present study.

The present study only partially supported the findings reported in Jakobosen and Jensen (2008) and in Alves et al (2010) that all participants (as a group) significantly have longer mean fixation duration insight translation than it in reading for summary or reading for translation. The statistical paired samples $t$ test of fixation duration findings in present study also showed more significant differences across groups including the increases from Task 1 to Task $4(\mathrm{p}<0.05, \mathrm{t}=-2.537$, and $\mathrm{df}=11)$, from Task 2 to Task $4(\mathrm{p}<0.05, \mathrm{t}=-2.716$, and $\mathrm{df}=11)$ and from Task 3 to Task $4(\mathrm{p}<0.05, \mathrm{t}=--2.765$, and $\mathrm{df}=11)$. The present study claims another finding that professionals had much shorter fixations than students in Task 1, 2 and 3. Yet professionals had slightly longer fixations than students in Task 4. So Hypothesis 3 that subjects would have longer fixations as they dealt with increasing complexity of the tasks requested was partially confirmed and students would spend more time than professionals do when they perform the same task was also partiallyconfirmed.

Reading a text while speaking a translation of it involved longer fixations because the gaze was used not only to read the text for comprehension but subsequently to visually monitor the portions of ST as their translation was spoken. In sight translation, participants need to translate a text orally while reading it. It is a process combining reading a text with producing a spoken translation at the same time. It required a different kind of reading that included visual monitoring of the progress of translation. This indicates that monitoring reading while engaging in a concurrent task (speaking or typing a translation) simultaneously causes both more fixations and fixations with longer average duration, so that total gaze time is increased owing to both these parameters (Jakobosen \& Jensen, 2008, p. 119).

Our study shows that there is no significant difference between reading for summary and reading for translation for all subjects in mean task time, mean fixation count and mean fixation duration. We may safely infer that at least some underlying reading and comprehension processes were operating in common in these two tasks. Some of this effect may be related to general language processes involved in language conversion. The study indicated that reading for translation have much in common with other kinds of reading tasks, especially with reading for summary, where language conversion is required by both the tasks.

In present study, no significant difference was found among reading for comprehension, reading for summary and reading for translation for subjects in mean fixation duration indicating that the interpreters appeared to have been affected by some of the comprehension and recoding issues that the translation task poses, but not to an extraordinary degree. They did not appear to try to solve all of the translation problems (or consider their solutions) during the reading task, since, given the nature of the task described to them, they expected to have enough time available to do this later.

Alves et al (2009) once pointed out that filter configuration is probably an intervening variable for comparability across experimental studies using eye tracking. Parameters to include or exclude fixation data in the analysis is usually determined by filter configuration. Fixation filters are responsible for how fixation data, such as fixation count, duration, and location, is calculated. This data in turn affects how gaze plots, heat maps, clusters, and eye tracking metrics are inferred. Tobii Studio provide four types of filter for users to choose, named I-VT filter, Tobii fixation filter, ClearView Fixation filterand Raw Data. The Tobii I-VT filter is developed to 
work for stationary eye trackers. In most cases the Tobii I-VT fixation filter will correctly classify fixations in recordings made with previous versions of Tobii Studio. Bearing the importance of filter setting in mind, the present study chooses Tobii I-VT filter to collect the data. The differences among the findings of the present study and the findings in Jakobosen and Jensen (2008) and in Alves et al (2010) are likely to be related to eye-tracking data filter configurations owing to the use of different soft packages namely Clear view for Jakobosen and Jensen (2008), Tobii Studio (filters unknown) for Alves et al (2010) and Tobii I-VT filter for the present study.

Table 6

Comparison of Mean Fixation Duration in Three Studies

\begin{tabular}{lll}
\hline & By Tasks & By Groups \\
\hline J \&J & Task 1/Task 2<Task 4 & No difference \\
Alves & Task 1/Task 3<Task 4 & Not mentioned \\
Present Study & Task 1/Task 2/Task3<Task 4 & S $>$ P(task 1, task 2 and task 3) \\
\hline
\end{tabular}

\section{Conclusion}

Adopting an analogous experimental design to Jakobsen \& Jensen (2008) and Alves et al. (2010), the present study investigated interpreters' eye movement behavior in E-C language pair. The results show that by groups interpreters did spend more task time, more and longer fixationsas they dealing with increasing complexity of the tasks requested. Across groups student interpreters spend more time, more and longer fixationsin reading tasks than do professionals in most of the tasks.As task time, fixation counts and fixation duration are assumed to be indicators of the subjects' cognitive effort in the given translation task, the increasing cognitive efforts required by reading in this study is dependent on various reading tasks and translation expertise, which provided tentative implications for understanding and modelling the way interpreters read.

By comparing our findings with the findings reported in Jakobsen \& Jensen (2008) and Alves et al (2010), we conclude that our findings in the investigation of interpreters' eye movement behavior across different tasks in E-C language pair confirmed most of the findings reported in Jakobsen \& Jensen (2008), and partially confirmed the findings reported Alves et al (2010). Possible reasons for the similarities and differences are also discussed in the study.

The resent study reinforced Alves et al's $(2009,2010)$ claim that it is vital to set accurate methodological procedures in the comparison of studies and filter configuration is probably an intervening variable for comparability across experimental studies using eye tracking.It also pointed out the importance of filter settings in to allow the comparison of studies.

\section{References}

Alves, F., Pagano, A., \& da Silva, I. (2010). Towards an investigation of reading modalities in/for translation: An exploratory study using eye-tracking data. Cognitive explorations of translation. London: Continuum, 175, 192.

Alves, F., Pagano, A., \& da Silva, I. (2009) A new window on translators' cognitive activity: methodological issues in the combined use of eye tracking, key logging and retrospective protocols. In Mees, M. Inger, F. Alves, \& S. Göpferich (Eds.), Methodology, technology and innovation in translation process research (pp. 267-292). Copenhagen: Samfundslitteratur.

Brychtova, A., \& Coltekin, A. (2016). An empirical user study for measuring the influence of colour distance and font size in map reading using eye tracking. The Cartographic Journal, 53(3), 202-212. 
Carl, M., Bangalore, S., \& Schaeffer, M. (Eds.). (2016). New directions in empirical translation process research. London: Springer.

Danks, J. H., \& Griffin, J. (1997). Reading and translation: A psycholinguistic perspective. APPLIED PSYCHOLOGY-LONDON-SAGE-, 3, 161-175.

Ferreira, A., Schwieter, J. W., Gottardo, A., \& Jones, J. (2016). Cognitive effort in direct and inverse translation performance: Insight from eye-tracking technology. Cadernos de Tradução, 36(3), 60-80.

Göpferich, S., Jakobsen, A. L., \& Mees, I. M. (2008). Looking at eyes: Eye-tracking studies of reading and translation processing. Copenhagen: Samfundslitteratur.

Grucza, S., Pluzyczka, M., \& Zajac, J. (2013). Translation studies and eye-tracking analysis. Frankfurt am Main: Peter Lang.

Jakobsen, A. L., \& Jensen, K. T. (2008). Eye movement behaviour across four different types of reading task. Copenhagen Studies in Language, (36), 103-124.

Jakobsen, A. L. (2017). Translation process research. In A. Ferreira, \& J. W. Schwieter (Eds.), The Handbook of Translation and Cognition (pp. 21-49). Hoboken: John Wiley \& Sons.

Linderholm, T., Cong, X., \& Zhao, Q. (2008). Differences in low and high working-memory capacity readers' cognitive and metacognitive processing patterns as a function of reading for different purposes. Reading Psychology, 29(1), 61-85.

Macizo, P., \& Bajo, M. T. (2004). When translation makes the difference: Sentence processing in reading and translation. Psicologica: International Journal of Methodology and Experimental Psychology, 25(1), 181-205.

Macizo, P., \& Bajo, M. T. (2006). Reading for repetition and reading for translation: Do they involve the same processes?. Cognition, 99(1), 1-34.

Pavlović, N., \& Jensen, K. (2009). Eye tracking translation directionality. Translation Research Projects, 2, 93-109.

Rayner, K. (1998). Eye movements in reading and information processing: 20 years of research. Psychological Bulletin, 124, $372-422$.

Rayner, K., \& Pollatsek, A. (1989). The Psychology of Reading. Englewood Cliffs, N. J.: Prentice Hall.

Ruiz, C., Paredes, N., Macizo, P., \& Bajo, M. T. (2008). Activation of lexical and syntactic target language properties in translation. Acta psychologica, 128(3), 490-500.

Pavlović, N., Jensen, K. (2009). Eye tracking translation directionality. Translation Research Projects, 2, 93-109.

Shreve, G. M., Schäffner, C., Danks, J. H., \& Griffin, J. (1993). Is there a special kind of "reading” for translation?: An empirical investigation of reading in the translation process. Target. International Journal of Translation Studies, 5(1), 21-41.

\section{Appendix A}

Historic day as Blair surrenders power and Brown finally moves into No 10.

Tony Blair surrendered on his own terms today as Gordon Brown ushered in a new radical era of change. Ending a decade of relentless controversy, wars and even a police inquiry, Labour's longest-serving Prime Minister was set to stroll out of No 10 with his head held high. It is also the day Mr Blair is expected to announce that he is turning his back on British politics for good to take up a job as special envoy to the Middle East. He is poised to resign as an MP on the same day he steps down as Prime Minister triggering a by-election in his constituency of Sedgefield, which could be held as early as July 19.

His decision to stand down after 24 years in Parliament will allow him to 'throw himself' into the role as the international community's key peacemaker in the Middle East, his close allies said. Today at Downing Street, crowds of well-wishers, and protesters were gathering in Whitehall to watch, cheer or jeer his final progress from Downing Street to the Commons for his final Prime Minister's Questions.

\section{Finally, Blair exits the stage}

Tony Blair will say farewell to Downing Street and domestic politics today, bringing to an end a remarkable decade in power which began with extraordinarily high hopes but ended with opinion divided over his legacy to the country. After his last 
appearance at the dispatch box at Prime Minister's questions Mr Blair will return to Downing Street to make an emotional farewell to his staff, some of whom have been with him since he became Leader of the Opposition in the heady days of 1994 and the birth of New Labour.

Mr Blair, Labour's most successful leader after an unprecedented three election victories, making him - alongside Margaret Thatcher - one of the dominant political figures since the war, will drive up The Mall to Buckingham Palace with his wife Cherie to tender his resignation to the Queen. In contrast to his arrival as Prime Minister in May 1997 when Downing Street was lined with handpicked Labour Party members cheering, and waving Union flags, Mr Blair will make a low-key exit. Today it will be photographers, not supporters, recording his reluctant departure.

\section{Blair exits British politics as new era begins with a Tory defection}

A new political order in Britain will take shape this afternoon when Tony Blair flies to his Sedgefield constituency to resign from parliament with immediate effect, and Gordon Brown enters No 10 to prepare a shakeup of government which will see at least

six ministers quit the cabinet. Mr Brown's allies said the new ministerial line-up would be deliberately inclusive, and not settle scores with Mr Blair's supporters. Mr Blair had planned to keep the decision to quit as an MP secret until after his 318th and final prime minister's questions at noon today. But news leaked that his local party was being called to an extraordinary meeting to be addressed tonight by Mr Blair.

Two of his aides in No 10 are expected to join him in his new life as a Middle East envoy. If, as expected, the role is confirmed today, Mr Blair will resign as an MP, triggering a byelection which may take place as early as July. His departure from parliament means his earnings from the lecture circuit will be kept from the register of members' interests.

\section{Blair may quit as MP if he gets role in Middle East}

Tony Blair will stand down as Labour MP for Sedgefield if, as expected, he is appointed as a special international envoy to the Middle East today. The Prime Minister's move will trigger a by-election in the County Durham constituency he has represented since 1983, where he has a majority of $18,449$.

On his last full day as Prime Minister, Mr Blair made clear he was keen to be appointed as an envoy for the Quartet - the US, the EU, the UN and Russia. "I think that anybody who cares about greater peace and stability in the world knows that a lasting and enduring resolution of the Israeli-Palestinian issue is essential," he said.

He was speaking at a joint press conference with Arnold Schwarzenegger, the Governor of California. Mr Blair was in a relaxed mood, but did not want to upset his successor. Asked if he had advice for the new Prime Minister, he replied: "No ... because he is perfectly capable of doing the job on his own, thank you."

US president George Bush last night paid tribute to the "very talented" Tony Blair. 